\title{
Leptomeningeal dissemination of a low-grade lumbar paraganglioma: case report
}

\author{
Nick Thomson, MD, ${ }^{1}$ Karel Pacak, MD, PhD, DSc, ${ }^{2}$ Meic H. Schmidt, MD, MBA, ${ }^{3,9}$ \\ Cheryl A. Palmer, MD, ${ }^{4,9}$ Karen L. Salzman, MD, ${ }^{5,9}$ Marjan Champine, MS, CGC, ${ }^{6,9}$ \\ Joshua D. Schiffman, MD, 7,9 and Adam L. Cohen, MD, MS 8,9
}

\begin{abstract}
'Department of Internal Medicine, University of Arizona College of Medicine Phoenix, Arizona; ${ }^{2}$ Section on Medical Neuroendocrinology, National Institutes of Health, Bethesda, Maryland; Departments of ${ }^{3}$ Neurosurgery; ${ }^{4}$ Pathology, Division of Anatomic Pathology; ${ }^{5}$ Radiology, Division of Neuroradiology; ${ }^{6}$ Population Health Sciences; ${ }^{7}$ Pediatrics and Oncological Sciences; and ${ }^{8}$ Medicine, Division of Oncology, University of Utah, Salt Lake City; and ${ }^{~ H H u n t s m a n ~ C a n c e r ~ I n s t i t u t e, ~ S a l t ~ L a k e ~ C i t y, ~ U t a h ~}$
\end{abstract}

Leptomeningeal dissemination of paraganglioma is rare, with only 2 prior cases in the literature. The authors present the case of a metastatic low-grade lumbar paraganglioma via leptomeningeal dissemination. This report emphasizes the utility of 3,4-dihydroxy-6- ${ }^{18} \mathrm{~F}$-fluoro-L-phenylalanine ( ${ }^{18} \mathrm{~F}$-FDOPA) PET scanning for diagnosis, as well as the combination of radiation therapy and alkylating chemotherapeutic agents for the treatment of this rare phenomenon. The patient was a 61-year-old woman who presented with low-back pain and was found to have an isolated L-3 intrathecal tumor on MRI. Sixteen months after gross-total en bloc resection of the paraganglioma, the patient again became symptomatic with new neurological symptoms. MRI findings revealed enhancing leptomeningeal nodules throughout the spine. ${ }^{18} \mathrm{~F}-\mathrm{FDOPA}$ $\mathrm{PET} / \mathrm{CT}$ scanning was used to confirm the diagnosis of disseminated paraganglioma. Intrathecal thiotepa, radiation therapy, and systemic therapy with capecitabine and temozolomide have been used sequentially over a 2-year period, with each able to stabilize tumor growth for several months. The authors also summarize the 2 other reports of leptomeningeal dissemination of paragangliomas in the literature and compare the course and management of the 3 cases.

https://thejns.org/doi/abs/10.3171/2016.10.SPINE16948

KEY WORDS paraganglioma; spinal neoplasm; neuroendocrine tumor; metastasis; lumbar; oncology

$\mathrm{P}$ ARAGANGLIOMAS are rare, extra-adrenal neuroendocrine tumors derived from embryonic neural crest cells. They are classified as functioning or nonfunctioning based on their ability to produce catecholamines. If nonfunctional, they are mostly asymptomatic and are typically discovered incidentally. If functional, they may secrete catecholamines, leading to clinical presentations similar to adrenal pheochromocytomas, including episodic headaches, hypertension, sweating, and tachycardia. Most paragangliomas are benign; however, $15 \%$ to $35 \%$ may eventually become metastatic. ${ }^{14}$ Standard treatment for paraspinal paragangliomas below the neck is resection with adjuvant radiation therapy on an individualized basis. Despite complete excision, $20 \%$ of patients with primary extra-adrenal paragangliomas below the neck may develop recurrence. ${ }^{1}$ Leptomeningeal dissemination is a rare phenomenon, seen only in a small number of cases worldwide. $^{23}$

\section{Case Report}

History

A 61-year-old woman with no history of malignancy and a medical history of hypertension and Type 2 diabetes mellitus presented to her primary care physician with low-back pain in late 2011. She had no focal neurological signs or symptoms on initial presentation. MRI revealed an intrathecal tumor of the lumbar spine at the L-3 level (Fig. 1), without evidence of abnormalities throughout the rest of the spine or brain. 


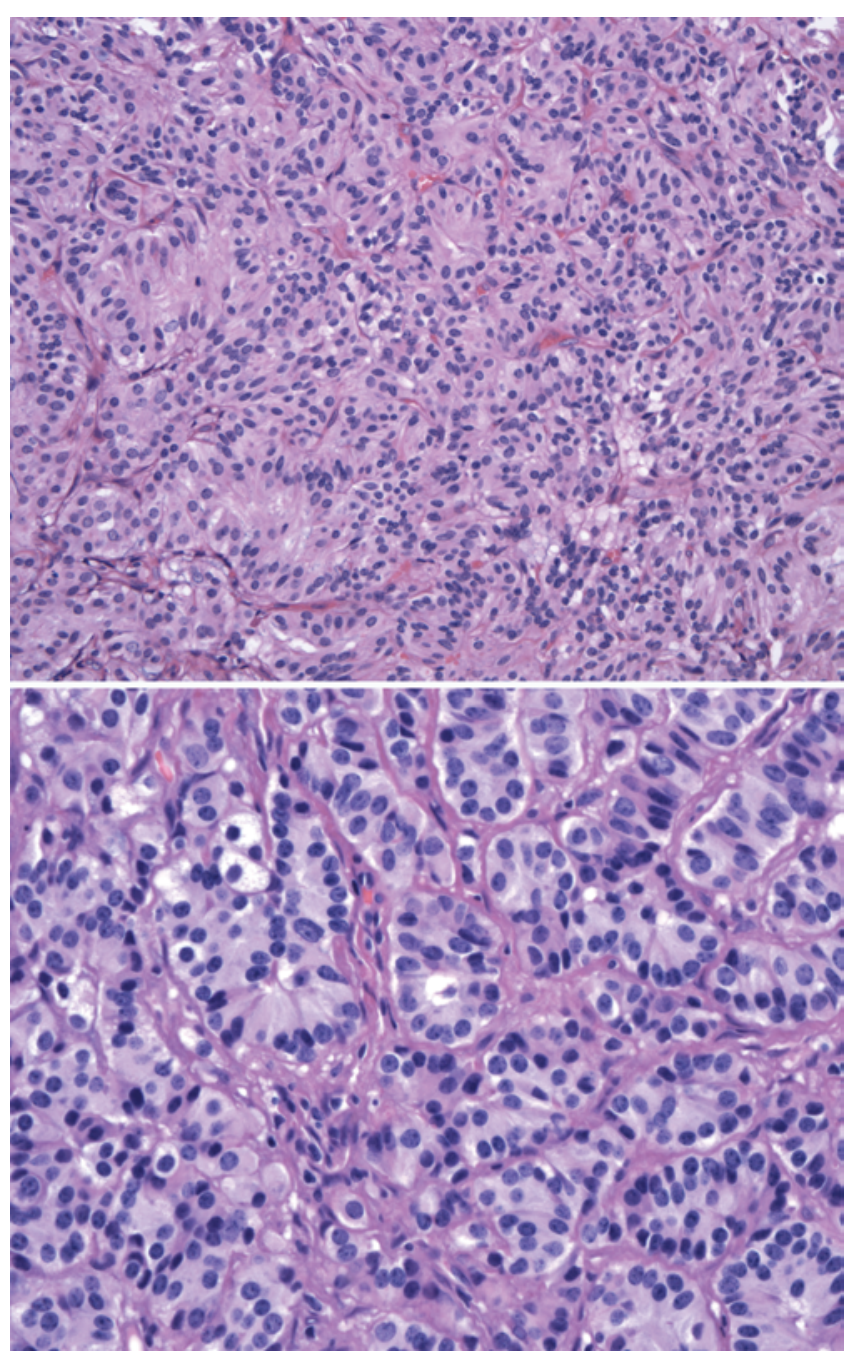

FIG. 1. Upper: Staining of the tumor reveals nests of cells (the classic Zellballen pattern) consisting of small ovoid nuclei and eosinophilic cytoplasm separated by thin, fibrovascular septae. Lower: Higher power image reveals the bland, stippled chromatin pattern and scattered nucleoli. $H$ \& E, original magnification $\times 200$ (upper); $\times 400$ (lower). Figure is available in color online only.

\section{Operation}

An L2-4 laminectomy was performed in February 2012. Notedly thin dura and arachnoid maters over the underlying tumor were opened to immediately reveal an encapsulated tumor originating from the filum. Arachnoid adhesions were carefully cauterized, after which a grosstotal en bloc resection of the extramedullary mass was performed without violating its capsule. Following the surgery, the patient experienced complete resolution of her low-back pain, but she did note residual rectal numbness and weakness without loss of bowel or bladder function.

\section{Pathological Examination}

Neuropathological examination demonstrated a thinly encapsulated, pink-tan to maroon tumor that was $4.6 \times 2.0$ $\times 1.8 \mathrm{~cm}$ in size. The tumor came within $0.6 \mathrm{~cm}$ of the nearest margin without evidence of dural sac invasion. It was estimated that complete macroscopic surgical remov-
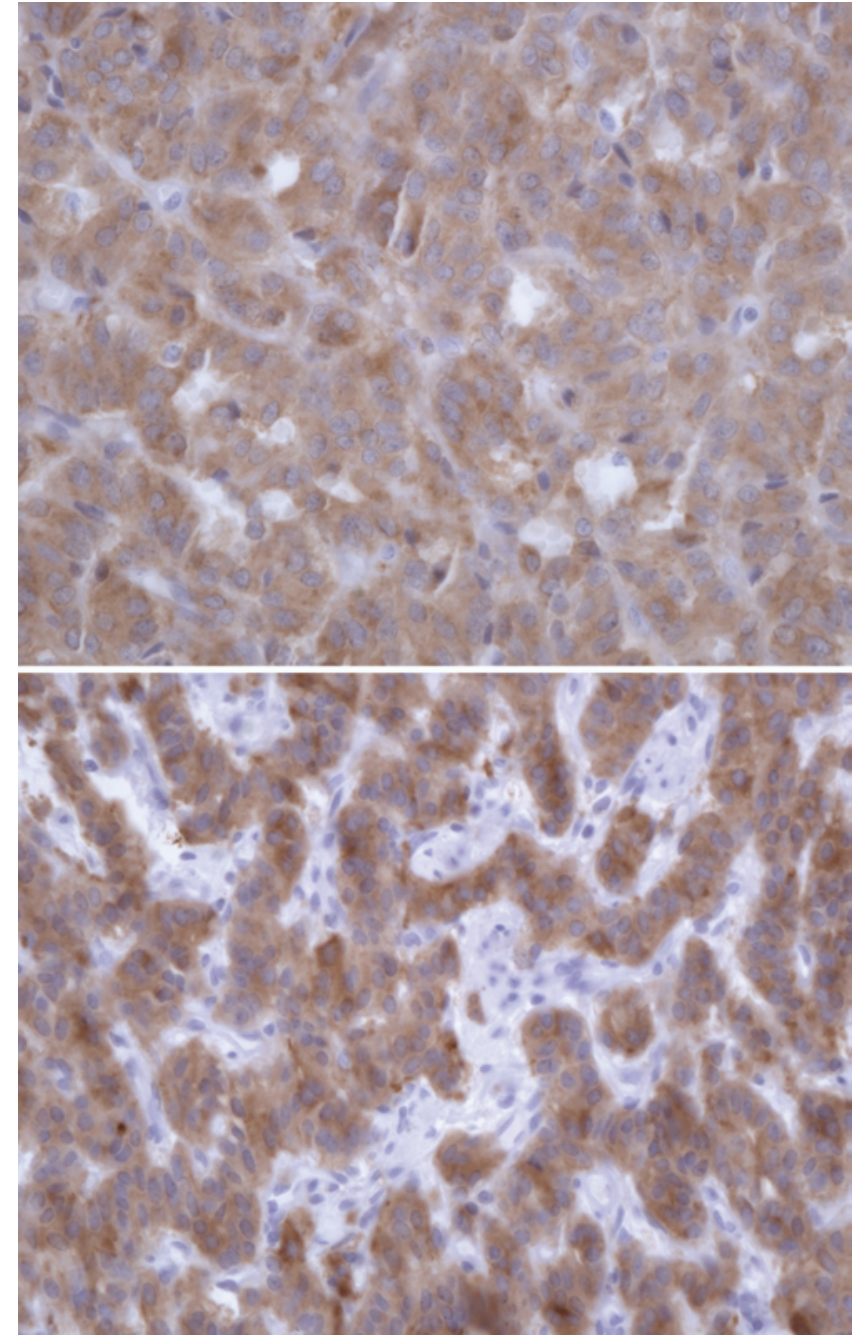

FIG. 2. The tumor is positive by immunohistochemical staining for nonspecific enolase (upper) and synaptophysin (lower). Original magnification $\times 400$. Figure is available in color online only.

al was attained. With $\mathrm{H} \& \mathrm{E}$ staining, the tumor contained relatively uniform, round-to-oval neoplastic cells arranged in nests (the classically described "Zellballen" pattern). Focal pseudorosetting patterns were seen. The nuclei were centrally located and displayed "salt and pepper"type chromatin. Moderate amounts of granular cytoplasm were present (Fig. 1). The tumor nests were surrounded by delicate monolayers of thin, elongated sustentacular cells. Fragments of bone were included in the tumor matrix. Immunohistochemical staining performed on the tumor revealed it to be positive for nonspecific enolase and synaptophysin (Fig. 2), both stains of neuroendocrine origin, and negative for glial fibrillary acidic protein and epithelial membrane antigen. The histopathology was diagnostic of a paraganglioma.

\section{Molecular Genetics}

Germline genetic testing revealed no clinically significant alteration in the $S D H B, S D H C$, or $S D H D$ genes; however, a variant of unknown clinical significance, p.H50R or c.149A $>\mathrm{G}$, in exon 2 of the $S D H D$ gene was identified. 

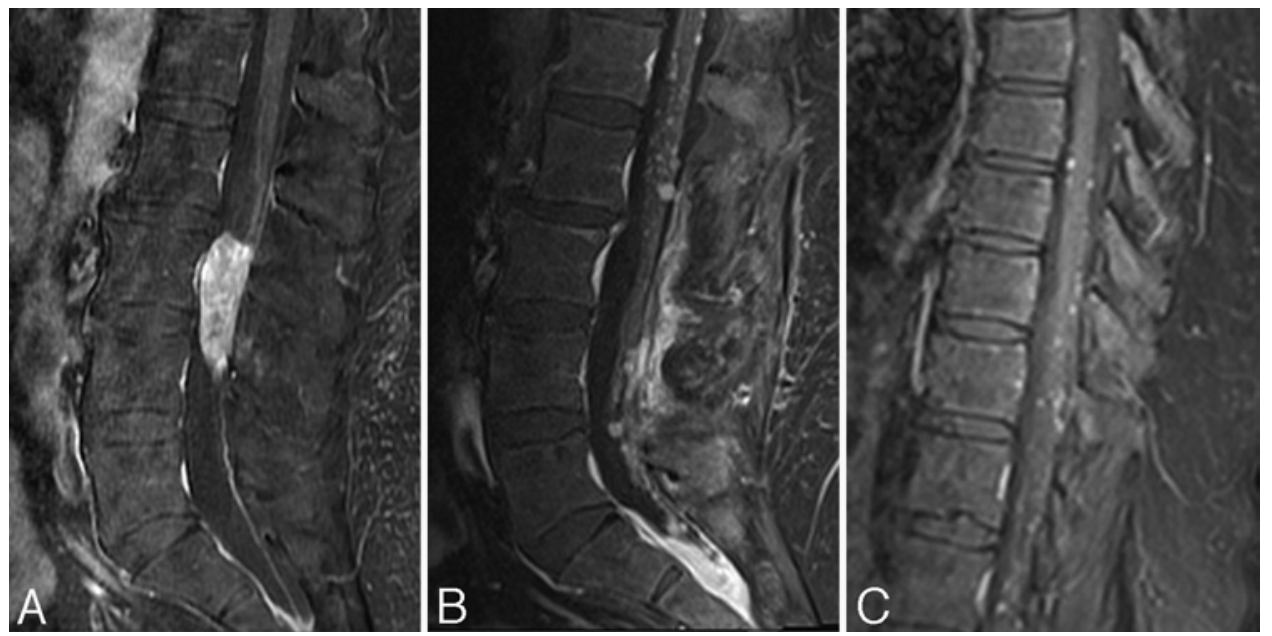

FIG. 3. A and B: Sagittal T1-weighted postcontrast MR images showing an enhancing mass at presentation (A) and enhancing recurrence at 17 months in the lumbar spine (B), including dependently in the inferior thecal sac, in addition to postoperative changes from prior mass resection. C: Sagittal T1-weighted postcontrast MR image depicting thoracic metastases at 17 months.

It is not currently confirmed to be deleterious or causative of classic hereditary paraganglioma syndrome, and it is known to exist in the general population of healthy individuals with a frequency of approximately $3 \% .^{3}$ Sitespecific genetic testing for this alteration was offered to the patient's parents to clarify whether it may have been associated with her paraganglioma; however, this offer was declined. Plasma metanephrines were measured to be within normal limits $(<0.10 \mathrm{nmol} / \mathrm{L})$, as were urine and serum normetanephrine $(0.81 \mathrm{nmol} / \mathrm{L}$ in both samples).

\section{Postoperative Course}

Follow-up MRI at 6 months revealed no residual tumor. In June 2013, the patient developed acute-onset, severe low-back pain radiating down her right thigh and new-onset numbness of her right buttock. MRI revealed multiple, extensive leptomeningeal foci along the conus medullaris and nerve roots, spreading upward to the level of T-1 (Fig. 3 ), with no evidence of metastatic disease in the cervical spine or brain. Three separate lumbar punctures were performed with cytologies negative for malignancy. Given the location and size of the recurrent disease, biopsy was not feasible to confirm diagnosis.

3,4-dihydroxy-6- ${ }^{18} \mathrm{~F}$-fluoro-L-phenylalanine $\left({ }^{18} \mathrm{~F}-\mathrm{FDOPA}\right)$ is known to accumulate within neuroendocrine tumors. By synthetically attaching a radiotracer fluorine- 18 isotope to the FDOPA molecule and allowing cellular uptake via the neutral amino acid transporter (LAT1/4F2hc), a PET/ CT can then be used for precise localization of tumors. ${ }^{20}$ ${ }^{68} \mathrm{Ga}$-DOTATATE ${ }^{68} \mathrm{Ga}$-tetraazacyclododecane tetraacetic acid-octreotate) PET/CT may also be used for the detection of recurrent or metastatic paragangliomas. ${ }^{11,12}$ Our patient was referred to the National Institutes of Health, where findings on an ${ }^{18} \mathrm{~F}$-FDOPA PET/CT were positive for recurrent paraganglioma in the same distribution as the MRI findings (Fig. 4). Also tested at the National Institutes of Health were plasma chromogranin A, catecholamine, and metanephrine levels that were found to be within normal limits.

Due to concurrent unstable cardiac and pulmonary comorbidities, the patient was observed initially until her other conditions were treated. Once her cardiac and pulmonary conditions resolved, her back pain and numbness returned to the baseline levels she had had since her initial surgery. Because the extent of disease precluded curative treatment and her symptoms were at baseline, she was observed for a total of 9 months until March 2014, when she developed new-onset numbness of her lower extremities and accompanying worsening MRI findings. An Ommaya reservoir was placed for intrathecal delivery of thiotepa, which was given twice weekly for 6 weeks, followed by weekly treatments for 8 weeks. In August 2014, she developed progressive neurological symptoms in the S-1 distribution, similar to those that she previously experienced. MRI confirmed progression of her disease in the sacral spine, with multiple foci involving nerve roots of the cauda equina. The patient then received radiation therapy at the level of T-12 through the sacral spinal canal (45 Gy) with L2-sacral canal boost (50 Gy) from September to October 2014, which improved her neurological symptoms.

Because the patient's thoracic spine metastases had been stable on the intrathecal thiotepa, the sacral progression was thought to be due to poor penetration of the drug into the bulky sacral recurrence. Therefore, after the lumbosacral radiation therapy, intrathecal thiotepa was resumed, and serial MR images revealed stable disease. Intrathecal thiotepa was continued monthly until August 2015, when MRI revealed continued dissemination supe-
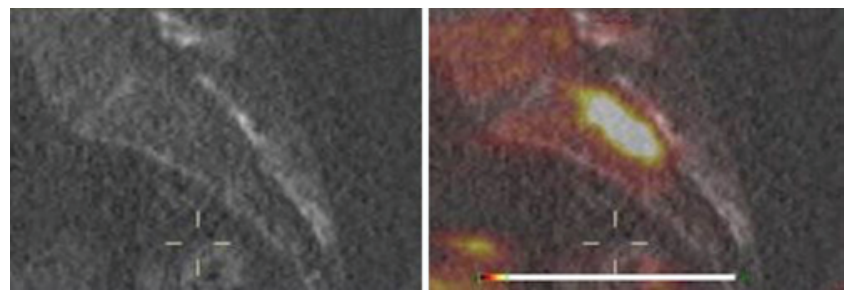

FIG. 4. Sagittal CT scan (left) compared with ${ }^{18} \mathrm{~F}$-fluorodopamine PET/ CT uptake scan (right) demonstrating recurrence of paraganglioma at 6 months. Figure is available in color online only. 
riorly throughout her cervical leptomeninges and into the cerebellum, where a 3-mm enhancing lesion was seen on the left side. Treatment was then changed to capecitabine and temozolomide, and repeat MRI through May 2016 revealed stable disease.

\section{Discussion}

Paragangliomas are mostly benign but do have significant recurrence rates that differ with site of disease and can recur decades after resection. ${ }^{24}$ Some studies have indicated metastasis rates of $28 \%$ to $42 \%$ for retroperitoneal paragangliomas. ${ }^{13,16}$ Carotid body tumors have been found to have the lowest metastatic rates $(2 \%-9 \%))^{15,22}$ Local recurrence after surgical excision is more common in patients with a genetic predilection compared with sporadic pathology and if the tumor is of extra-adrenal origin compared with adrenal tumors. ${ }^{1}$ Because of the few instances where dissemination of recurrent, macroscopically resected tumor has occurred, treatment must be determined on an individual basis.

Several targeted therapies are being developed for the treatment of metastatic paragangliomas. Peptide receptor radionuclide therapy has been shown to be effective in treating other neuroendocrine tumors and is possibly effective in the treatment of metastatic paragangliomas. ${ }^{17}$ However, somatostatin analogs used in peptide receptor radionuclide therapy do not cross the blood-brain barrier and are thus ineffective for the treatment of CNS disease. Paraganglioma cell-surface ATP (adenosine triphosphate) synthase has been demonstrated as another potential therapeutic target. ${ }^{10}$ Resveratrol, as well as other ATP synthase targets, has been shown to potentially cross the blood-brain barrier. ${ }^{26}$ Further development and study of these and other novel systemic and localized treatment modalities is necessary for the advancement of treating metastatic paragangliomas.

For paragangliomas located below the neck, radiation therapy is typically used only for painful bony lesions or tumors with rapid growth. ${ }^{5}$ Although paragangliomas were once thought to be resistant to radiation, ${ }^{6}$ our case and those of others have demonstrated that radiation therapy can effectively palliate symptoms and stop growth of paraganglioma. ${ }^{8,25}$

A review of the literature was performed to identify all reported cases of leptomeningeal dissemination of paraganglioma. A comparison of our case with that of 2 similar cases from Switzerland ${ }^{23}$ and Sweden ${ }^{19}$ reveals many similarities (Table 1). In all 3 circumstances, the paragangliomas were initially small and encapsulated and were located in the lumbosacral area, making total resection plausible. Given the anatomical locations of these lesions, local recurrence and dissemination likely occurred via the spinal subarachnoid space rather than the cerebrospinal fluid. In all 3 instances, metastatic disease was found within the cerebellum. In 2 cases, radiation therapy was successful at controlling progressive metastases. Our case also highlights that alkylating agents that penetrate the CNS can produce disease stability in leptomeningeal paraganglioma.

These cases demonstrate that although maximal safe resection is important, en bloc total resection may not prevent local dissemination through the meninges. They also illustrate that radiation therapy and alkylating agents, given either intrathecally or systemically, are active against paraganglioma. In all 3 cases, histological or genetic characteristics were initially indistinguishable from other benign paragangliomas, giving no hint of their later leptomeningeal spread. ${ }^{7}$

Identification of new biomarkers to assess the aggressiveness of these tumors is needed to identify those patients who may benefit from adjuvant therapy. A high $\mathrm{Ki}-67$ index has been proposed as a potential prognostic factor. A recent study evaluated 3'-deoxy-3'-18 F-fluorothymidine $\left({ }^{18} \mathrm{~F}-\mathrm{FLT}\right) \mathrm{PET} / \mathrm{CT}$, a PET proliferation tracer, as a potential radioimaging agent in a series of paraganglioma

TABLE 1. A comparison of 3 cases of metastatic paragangliomas

\begin{tabular}{|c|c|c|c|c|c|c|}
\hline $\begin{array}{l}\text { Authors \& } \\
\text { Year }\end{array}$ & $\begin{array}{l}\text { Location of } \\
\text { Primary }\end{array}$ & $\begin{array}{c}\text { Time to } \\
\text { Dissemination }\end{array}$ & $\begin{array}{l}\text { En Bloc } \\
\text { Resection }\end{array}$ & $\begin{array}{c}\text { Sites of } \\
\text { Dissemination }\end{array}$ & Treatment of Recurrence & Survival \\
\hline $\begin{array}{l}\text { Present } \\
\text { study }\end{array}$ & $\begin{array}{l}\text { Intrathecal } \\
\text { at L-3 }\end{array}$ & $6 \mathrm{mos}$ & Yes & $\begin{array}{l}\text { Conus medullaris, cauda } \\
\text { equina nerve root, tho- } \\
\text { racic spine, cerebellum }\end{array}$ & $\begin{array}{l}\text { XRT, intrathecal thiotepa, \& } \\
\text { CAPTEM }\end{array}$ & $\begin{array}{c}\text { Alive as of August } 2016 \text { (>5.5 } \\
\text { yrs after diagnosis) }\end{array}$ \\
\hline $\begin{array}{l}\text { Strommer } \\
\text { et al., } \\
1995\end{array}$ & $\begin{array}{l}\text { Intradural } \\
\text { at L-3 }\end{array}$ & 22 yrs & Yes & $\begin{array}{l}\text { Multiple posterior fossa } \\
\text { metastases: cerebellar } \\
\text { declive, culmen \& rt floc- } \\
\text { culus, It inferior colliculus, } \\
\text { as well as recurrence } \\
\text { at original site, \& in the } \\
\text { cauda equina at L4-S1 }\end{array}$ & $\begin{array}{l}\text { Median suboccipital craniotomy } \\
\text { at which time cystic midline } \\
\text { cerebellar lesion \& tumor were } \\
\text { removed but other lesions } \\
\text { were left behind; later (1993), } \\
\text { hemilaminectomy of L4-5 \& } \\
\text { S-1 w/ gross-total resection }\end{array}$ & $\begin{array}{l}\text { Alive as of } 1994 \text { when manu- } \\
\text { script was submitted }\end{array}$ \\
\hline $\begin{array}{l}\text { Roche } \\
\text { et al., } \\
1996\end{array}$ & $\begin{array}{l}\text { Intraspinal } \\
\text { from L-4 } \\
\text { to S-1 }\end{array}$ & 3 yrs & No & $\begin{array}{l}\text { Conus medullaris, rt CPA, } \\
\text { cerebellar culmen, tho- } \\
\text { racic spinal cord, conus }\end{array}$ & $\begin{array}{l}\text { Gross-total removal of CPA } \\
\text { tumor; however, small } \\
\text { subarachnoidal lesions were } \\
\text { identified but not resected; } \\
\text { XRT to the craniospinal drop } \\
\text { neoplasms }\end{array}$ & $\begin{array}{l}4.5 \text { years after initial surgery ( } 6 \\
\text { mos after CPA recurrence, } \\
\text { patient had fluid \& electro- } \\
\text { lyte imbalance following } \\
\text { surgical intervention of small } \\
\text { bowel obstruction \& died) }\end{array}$ \\
\hline
\end{tabular}


patients with varying genetic backgrounds to compare ${ }^{18} \mathrm{~F}$-FLT uptake with ${ }^{18} \mathrm{~F}$-FDG PET/CT and evaluate classic factors of aggressiveness. There was no superiority of ${ }^{18} \mathrm{~F}$-FLT uptake in progressive lesions, suggesting the possibility that proliferation may not be a major indicator of aggressiveness. ${ }^{2}$ Genetic biomarkers are also being developed as prognostic indicators. A recent study demonstrated that $53 \%$ of patients with at least 1 extra-adrenal paraganglioma had an identified germline mutation. ${ }^{9}$ The most commonly mutated susceptibility gene associated with pheochromocytomas and paragangliomas is succinate dehydrogenase subunit $\mathrm{B}(S D H B)$, which also carries the highest risk of malignancy. ${ }^{9,21}$ In patients with $S D H B$ mutations, primary tumor size has been found to be an age-independent predictor of patient survival and metastasis. ${ }^{21}$ Age at diagnosis has also been found in these patients to be a size-independent predictor of patient survival. ${ }^{21}$ To achieve the best possible clinical outcome, patients discovered to have any $S D H$ mutation are recommended to undergo genetic counseling ${ }^{18}$ and early and regular evaluations for the development of pheochromocytomas/ paraganglioma.

To date, there are no large studies describing specific outcomes of metastatic paragangliomas initially located below the neck. This is, in part, due to the indolent, insidious nature of the disease, even in the setting of dissemination. In addition, the optimal therapeutic strategy for disseminated low-grade paragangliomas has yet to be defined. From our experience, we believe that alkylating chemotherapeutic agents and radiation therapy are both active modalities. It is possible that gene-targeted radiotherapeutics and other novel targeting moieties will be used in the future. ${ }^{4}$ Further studies are warranted to assess treatment outcomes in patients with this uncharacteristic modality of disease metastasis, with comparison of current treatment protocols and newly developed models as they become available. We also wish to emphasize the important utility of ${ }^{18} \mathrm{~F}$-FDOPA scans in the diagnosis of unresectable, small-sized disease where biopsy is not feasible. Documentation of atypical cases such as this one is central to clinician awareness in addition to the promotion of developing novel biomarkers for malignant potential and original treatment protocols.

\section{References}

1. Amar L, Servais A, Gimenez-Roqueplo AP, Zinzindohoue F, Chatellier G, Plouin PF: Year of diagnosis, features at presentation, and risk of recurrence in patients with pheochromocytoma or secreting paraganglioma. J Clin Endocrinol Metab 90:2110-2116, 2005

2. Blanchet EM, Taieb D, Millo C, Martucci V, Chen CC, Merino $\mathrm{M}$, et al: ${ }^{18} \mathrm{~F}-\mathrm{FLT}$ PET/CT in the evaluation of pheochromocytomas and paragangliomas: a pilot study. J Nucl Med 56:1849-1854, 2015

3. Cascon A, Ruiz-Llorente S, Cebrian A, Telleria D, Rivero JC, Diez JJ, et al: Identification of novel SDHD mutations in patients with phaeochromocytoma and/or paraganglioma. Eur J Hum Genet 10:457-461, 2002

4. Castinetti F, Kroiss A, Kumar R, Pacak K, Taieb D: 15 years of paraganglioma: imaging and imaging-based treatment of pheochromocytoma and paraganglioma. Endocr Relat Cancer 22:T135-T145, 2015
5. Chen H, Sippel RS, O’Dorisio MS, Vinik AI, Lloyd RV, Pacak K: The North American Neuroendocrine Tumor Society consensus guideline for the diagnosis and management of neuroendocrine tumors: pheochromocytoma, paraganglioma, and medullary thyroid cancer. Pancreas 39:775-783, 2010

6. Drasin H: Treatment of malignant pheochromocytoma. West J Med 128:106-111, 1978

7. Eisenhofer G, Tischler AS, de Krijger RR: Diagnostic tests and biomarkers for pheochromocytoma and extra-adrenal paraganglioma: from routine laboratory methods to disease stratification. Endocr Pathol 23:4-14, 2012

8. Fishbein L, Bonner L, Torigian DA, Nathanson KL, Cohen DL, Pryma D, et al: External beam radiation therapy (EBRT) for patients with malignant pheochromocytoma and nonhead and -neck paraganglioma: combination with ${ }^{131}$ I-MIBG. Horm Metab Res 44:405-410, 2012

9. Fishbein L, Merrill S, Fraker DL, Cohen DL, Nathanson KL: Inherited mutations in pheochromocytoma and paraganglioma: why all patients should be offered genetic testing. Ann Surg Oncol 20:1444-1450, 2013

10. Fliedner SMJ, Yang C, Thompson E, Abu-Asab M, Hsu CM, Lampert G, et al: Potential therapeutic target for malignant paragangliomas: ATP synthase on the surface of paraganglioma cells. Am J Cancer Res 5:1558-1570, 2015

11. Jain TK, Basher RK, Shukla J, Bhattacharya A, Prakash M, Mittal BR: Ga-68 DOTA-NOC PET/CT for the detection of residual/recurrence in a rare case of sacral spinal canal paraganglioma. World J Nucl Med 15:71-72, 2016

12. Janssen I, Chen CC, Millo CM, Ling A, Taieb D, Lin FI, et al: PET/CT comparing ${ }^{68} \mathrm{Ga}$-DOTATATE and other radiopharmaceuticals and in comparison with CT/MRI for the localization of sporadic metastatic pheochromocytoma and paraganglioma. Eur J Nucl Med Mol Imaging 43:17841791, 2016

13. Lack EE, Cubilla AL, Woodruff JM, Lieberman PH: Extra-adrenal paragangliomas of the retroperitoneum: A clinicopathologic study of 12 tumors. Am J Surg Pathol 4:109-120, 1980

14. Lee JA, Duh QY: Sporadic paraganglioma. World J Surg 32:683-687, 2008

15. Nora JD, Hallett JW Jr, O’Brien PC, Naessens JM, Cherry KJ Jr, Pairolero PC: Surgical resection of carotid body tumors: long-term survival, recurrence, and metastasis. Mayo Clin Proc 63:348-352, 1988

16. Olson JR, Abell MR: Nonfunctional, nonchromaffin paragangliomas of the retroperitoneum. Cancer 23:1358-1367, 1969

17. Pinato DJ, Black JRM, Ramaswami R, Tan TM, Adjogatse $\mathrm{D}$, Sharma R: Peptide receptor radionuclide therapy for metastatic paragangliomas. Med Oncol 33:47, 2016

18. Raygada M, King KS, Adams KT, Stratakis CA, Pacak K: Counseling patients with succinate dehydrogenase subunit defects: genetics, preventive guidelines, and dealing with uncertainty. J Pediatr Endocrinol Metab 27:837-844, 2014

19. Roche PH, Figarella-Branger D, Regis J, Peragut JC: Cauda equina paraganglioma with subsequent intracranial and intraspinal metastases. Acta Neurochir (Wien) 138:475-479, 1996

20. Santhanam P, Taïeb D: Role of ${ }^{18}$ F-FDOPA PET/CT imaging in endocrinology. Clin Endocrinol (Oxf) 81:789-798, 2014

21. Schovanek J, Martucci V, Wesley R, Fojo T, Del Rivero J, Huynh T, et al: The size of the primary tumor and age at initial diagnosis are independent predictors of the metastatic behavior and survival of patients with SDHB-related pheochromocytoma and paraganglioma: a retrospective cohort study. BMC Cancer 14:523, 2014

22. Shamblin WR, ReMine WH, Sheps SG, Harrison EG Jr: Carotid body tumor (chemodectoma). Clinicopathologic analysis of ninety cases. Am J Surg 122:732-739, 1971 
23. Strommer KN, Brandner S, Sarioglu AC, Sure U, Yonekawa Y: Symptomatic cerebellar metastasis and late local recurrence of a cauda equina paraganglioma. Case report. J Neurosurg 83:166-169, 1995

24. Van Slycke S, Caiazzo R, Pigny P, Cardot-Bauters C, Arnalsteen L, D'Herbomez M, et al: Local-regional recurrence of sporadic or syndromic abdominal extra-adrenal paraganglioma: incidence, characteristics, and outcome. Surgery 146:986-992, 2009

25. Vogel J, Atanacio AS, Prodanov T, Turkbey BI, Adams K, Martucci V, et al: External beam radiation therapy in treatment of malignant pheochromocytoma and paraganglioma. Front Oncol 4:166, 2014

26. Wang Q, Xu J, Rottinghaus GE, Simonyi A, Lubahn D, Sun GY, et al: Resveratrol protects against global cerebral ischemic injury in gerbils. Brain Res 958:439-447, 2002

\section{Disclosures}

Dr. Schmidt reports that he is a consultant for Ulrich Medical USA.

\section{Author Contributions}

Conception and design: Thomson, Cohen. Acquisition of data: Thomson, Pacak, Schmidt, Palmer, Salzman, Champine, Cohen. Analysis and interpretation of data: all authors. Drafting the article: Thomson. Critically revising the article: all authors. Reviewed submitted version of manuscript: all authors. Approved the final version of the manuscript on behalf of all authors: Thomson. Study supervision: Cohen.

\section{Supplemental Information}

Current Affiliations

Dr. Schmidt: New York Medical College, Westchester Medical Center \& Health Network, Valhalla, New York.

\section{Correspondence}

Nick Thomson, Department of Internal Medicine, University of Arizona College of Medicine Phoenix, 1111 E McDowell Rd., Phoenix, AZ 85006. email: thomson6@email.arizona.edu. 